\title{
ESTUDO COMPARATIVO DE TRÊS MÉTODOS DE AVALIAÇÃO DE TERRAS FLORESTAIS
}

\author{
Márcio Lopes da Silva¹, Renata Rodrigues de Castro Rocha², Sidney Araujo Cordeiro ${ }^{3}$, \\ Mayra Luiza Marques da Silva ${ }^{4}$, Adham Ferreira Bezerra ${ }^{4}$
}

(recebido: 19 de outubro de 2009; aceito: 25 de fevereiro de 2011)

\begin{abstract}
RESUMO: Tendo em vista que o estabelecimento de plantios florestais em propriedades rurais tem se tornado uma prática frequente onde o número de propriedades com plantações de culturas florestais é cada vez maior, torna-se necessário aprimorar as metodologias de avaliação destas propriedades com florestas, uma vez que a comercialização destas será uma prática cada vez mais comum. Portanto, objetivou-se, com este trabalho, realizar um estudo comparativo de três métodos de avaliação de terras florestais: valor de mercado, valor de custo e valor produtivo. Para isso, foi considerado um plantio de eucalipto cujo ciclo final de corte seria aos 7 anos. Os resultados mostraram uma grande diferença entre os métodos avaliados. O valor de mercado foi o que teve uma maior variação com o avançar da idade da floresta, se igualando ao valor produtivo no final do ciclo. No ano 0, o valor de mercado foi o que se mostrou com menores valores e no ano 7 o valor de custo foi o que se mostrou de menor valor. É importante que pesquisas e estudos mais específicos sejam realizados com o intuito de se obterem metodologias mais específicas para valorar este tipo de imóvel rural dada as suas peculiaridades.
\end{abstract}

Palavras-chave: Economia florestal, valor produtivo, valor de mercado, valor de custo.

\section{COMPARATIVE STUDY OF THREE FORESTLAND ASSESSMENT METHODS}

\begin{abstract}
Given the increasingly frequent practice of forest stand establishment in rural properties, with a steadily rising number of properties becoming home to forest crops, there is a pressing need to improve property assessment methodologies, as more and more crops will be entering the market. The objective of this work is thus to perform a comparative study of three methods of forestland assessment: market value, cost value and productive value. To that end, an eucalyptus stand with a 7-year final cutting cycle was considered. Results showed a substantial difference among methods. Market value provided greater variation with the advancing of forest age, equaling productive value toward the end of the cycle. In year 0 , market value provided the lowest values, while in year 7 cost value provided the lowest values. Further and more specific research and studies should be performed to obtain more specific methodologies to value this type of rural property and all of its peculiarities.
\end{abstract}

Key words: Forestry economy, productive value, market value, cost value.

\section{INTRODUÇÃo}

Nos últimos anos, o setor florestal brasileiro tem passado por diversas transformações, tanto no que diz respeito às técnicas utilizadas na produção de madeira, quanto no modelo de estabelecimento dos plantios florestais. É notório que nos dias atuais a atividade silvicultural está diretamente inserida no contexto econômico do país de maneira muito mais representativa, sendo esta vista como uma oportunidade para os produtores rurais.

Esse fato tem proporcionado a inserção de um novo modelo de produção de florestas, antes dominado por uma pequena quantidade de indústrias de base florestal, com grande extensão de áreas reflorestadas próximas ao mercado consumidor, neste caso as indústrias. Hoje já existem muitos produtores que plantam florestas em pequenas e médias propriedades rurais, visando obter mais uma fonte alternativa de renda. Esse crescimento de plantações florestais por parte dos pequenos e médios produtores tem sido influenciado diretamente por programas de fomento florestal desenvolvidos pelas empresas florestais atuantes no país.

O surgimento desse novo modelo de estabelecimento dos plantios florestais, em menores áreas e um maior número de propriedades, propõe a adoção de algumas metodologias para avaliação de imóveis rurais que possuam plantios florestais, uma vez que transações comerciais de imóveis com florestas, em idades variáveis e antes da idade de colheita, serão cada vez mais frequentes.

\footnotetext{
${ }^{1}$ Engenheiro Florestal, Professor Dr. em Ciência Florestal - Departamento de Engenharia Florestal/DEF - Universidade Federal de Viçosa/UFV 36570-000 - Viçosa, MG - marlosil@ufv.br

${ }^{2}$ Bacharel em Direito, Doutoranda em Ciência Florestal - Universidade Federal de Viçosa/UFV - 36570-000 - Viçosa, MG - rrcrocha@yahoo.com.br ${ }^{3}$ Engenheiro Florestal, Professor Dr. em Ciência Florestal - Departamento de Engenharias/CPCE - Universidade Federal do Piauí/UFPI - 64900-000 Bom Jesus, PI - sidneycordeiro@ufpi.edu.br

[4Engenheiro Florestal, Mestrando em Ciência Florestal - Universidade Federal de Viçosa/UFV - 36570-000 - Viçosa, MG - mayrasilva@yahoo.com.br, adhambezerra@hotmail.com
} 
Outro ponto importante a ser destacado é que cada imóvel deve ser analisado de maneira específica, observando as características da propriedade: solo, água, relevo, etc; e as características do plantio florestal: espécie, idade, produtividade, etc.

A finalidade dos métodos de avaliação de terras florestais, como o próprio nome diz, é de se proceder à avaliação de florestas para fins de compra e venda, indenização (incêndios), desapropriação (linhas de transmissão, estradas e barragens) e loteamento (SILVA et al., 2005).

Portanto, objetivou-se, com este trabalho, comparar três métodos de avaliação de terras florestais, analisando o impacto da utilização de cada um destes no preço final da propriedade por hectare, haja vista a tendência de mais pessoas comercializarem propriedades contendo reflorestamento antes do final do ciclo da cultura.

\section{MATERIAL E MÉTODOS}

\subsection{Fontes de dados}

Para o cálculo de valor de mercado da terra nua, foram utilizadas como fonte as informações contidas no Anuário da Agricultura Brasileira (AGRIANUAL, 2007), utilizando-se como referência o valor médio da terra agrícola para reflorestamento na região de Governador Valadares no ano de 2006, sendo este valor de R $\$ 2.843,25$ (dois mil oitocentos e quarenta e três reais e vinte e cinco centavos) por hectare. Tal região foi escolhida porque, dentre as outras cujos preços estão disponíveis no Agrianual (2007), somente esta precisa o valor terra agrícola destinada a reflorestamento, conferindo maior confiabilidade aos resultados.

Assim como o valor da terra nua, outras informações necessárias à análise foram extraídas do Agrianual (2007), tais como: custo de implantação, custo de manutenção e preço médio da madeira aos 7 anos.

Tais custos se referem às operações mecanizadas em todas as fases, as operações manuais, aos insumos, à administração, considerando uma densidade de 1660 árvores/ha e um espaçamento 3x2, sendo a espécie plantada E. urophilla ou E. urograndis.

Foi estabelecido um cenário com os custos do empreendimento florestal com eucalipto ao longo de um horizonte de 7 anos, conforme a Tabela 1. Vale ressaltar que o custo anual da terra é calculado multiplicando-se o valor da terra pela taxa de juros utilizada.

Cerne, Lavras, v. 17, n. 2, p. 209-213, abr./jun. 2011
Tabela 1 - Custos envolvidos no projeto de reflorestamento.

Table 1 - Costs involved in a reforestation project.

\begin{tabular}{lcc}
\hline Itens do Projeto & Ano de ocorrência & Valor R\$/ha \\
\hline Implantação & 0 & $\mathrm{R} \$ 1.811,00$ \\
Manutenção anual & $1-7$ & $\mathrm{R} \$ 278,00$ \\
Custo anual da terra & $1-7$ & $\mathrm{R} \$ 284,33$ \\
Taxa de Juros & $1-7$ & $10 \%$ \\
\hline
\end{tabular}

Fonte: Agrianual (2007).

Em relação às receitas, foi necessário estimar a produção do povoamento florestal. Para o cálculo da produção volumétrica do povoamento florestal, foi utilizado um modelo de relação volume em função da idade, devidamente ajustado (Equação 1) por Oliveira (2007).

$$
Y=\frac{476,7574}{\left(1+21,0233 e^{-0,0586 I}\right)}
$$

em que:

$Y=$ produção do alto fuste em $\mathrm{m}^{3} / \mathrm{ha}$;

$I=$ tempo em meses;

$e=$ base dos logaritmos neperianos.

Uma vez obtida a produção do povoamento, foi necessário estabelecer o preço da madeira para cada uma das idades, uma vez que esse preço varia de acordo com a idade/diâmetro do povoamento. O preço da madeira, para cada uma das idades, foi estabelecido mediante um preço inicial de $\mathrm{R} \$ 15,00 / \mathrm{m}^{3}$, sendo o preço de mercado da lenha para a idade de 1 ano. Considerou-se como preço de venda da madeira aos 7 anos $\mathrm{R} \$ 26,1 / \mathrm{m}^{3}$. A partir destes valores aplicou-se a fórmula abaixo para gerar a taxa de crescimento anual do preço.

$$
V_{n}=V_{0}(1+i)^{n}
$$

A tabela 2 mostra a produtividade da floresta bem como o respectivo preço da madeira ao longo do horizonte de 7 anos.

\subsection{Método do Valor de Mercado}

Este método, também denominado Método Comparativo de Dados de Mercado, é o procedimento mais utilizado, por sua relativa facilidade de uso e pela sua eficiência. É o mais indicado para determinação de mercado da terra nua, semoventes e de veículos. Por esse método, o valor de mercado é determinado pela comparação direta com outros imóveis semelhantes avaliados, cujas informações ou dados de mercado são obtidos valendo-se de 
Tabela 2 - Produtividade e valor da madeira ao longo da idade de povoamento.

Table 2 - Productivity and value of timber with the advancing of forest age.

\begin{tabular}{cccc}
\hline Ano & $\begin{array}{c}\text { Idade da Floresta } \\
\text { (em meses) }\end{array}$ & $\begin{array}{c}\text { Produção } \\
\left(\mathrm{m}^{3} / \text { ha }\right)\end{array}$ & $\begin{array}{c}\text { Valor da Madeira } \\
\text { em pé }\left(\mathrm{R} \$ / \mathrm{m}^{3}\right)\end{array}$ \\
\hline 0 & 0 & - & - \\
1 & 12 & 41,8 & 15,00 \\
2 & 24 & 77,5 & 16,50 \\
3 & 36 & 134,3 & 18,10 \\
4 & 48 & 210,8 & 19,80 \\
5 & 60 & 293,4 & 21,70 \\
6 & 72 & 364,1 & 23,80 \\
7 & 84 & 413,5 & 26,10 \\
\hline
\end{tabular}

Fonte: Elaborado pelos autores.

entrevistas, visitas técnicas, anúncios de jornais ou revistas, documentações de transferências, cadastro ou informações de corretores. Cabe, pois, ao avaliador comparar as informações de mercado, levando em consideração todas as características intrínsecas e extrínsecas do imóvel em relação aos paradigmas. (DESLANDES, 2002)

Deve-se lembrar também, que esse método é considerado rápido, fácil e eficiente, apenas se houver abundância de informações, tanto do próprio imóvel, quanto dos imóveis a que se comparar. Caso contrário, o método é falho, e isso é possível de acontecer em certas regiões do país, ou durante certas épocas, em que os dados não estejam atualizados e a movimentação no mercado de compra e venda de bens imóveis esteja um pouco estagnada.

Para a valoração da terra com base neste método, foi simulada a produtividade do plantio florestal ao longo dos anos de duração deste projeto (neste caso 7 anos) utilizandose o modelo de relação volume em função da idade, devidamente ajustado, citado ao longo do texto do artigo.

\subsection{Método do Valor de Custo}

O Método Valor de Custo ou Método de Custo de Reprodução baseia-se na hipótese de que um comprador, bem informado, não pagará por um imóvel mais do que o custo para construir outro igual (FIKER, 1997). É aquele em que o valor da edificação (bem) resulta de orçamento sumário ou detalhado, ou da comparação de custos de outros iguais aos que são objetos de avaliação (custo de reprodução) ou equivalentes (custos de substituição).

No caso de um imóvel com plantios florestais, este método leva em consideração todos os custos desprendidos para o estabelecimento do povoamento até a sua data de comercialização. Computa todos os gastos desde a aquisição da terra até a implantação e manutenção do projeto florestal.

\subsection{Método do Valor Produtivo}

Também conhecido como Método do Valor Econômico, baseia-se nos custos e em receitas futuras. Na avaliação de essências florestais homogêneas, será considerado o valor econômico da plantação que, no caso, pode ser equiparado ao valor presente do rendimento líquido dos desbastes periódicos vincendos e do corte final (ASSOCIAÇÃO BRASILEIRA DE NORMAS TÉCNICAS - ABNT, 2004).

Os terrenos e povoamentos florestais constituem o capital básico de qualquer empresa florestal. Uma tarefa importante do manejador é estabelecer um valor para o povoamento, para a terra ou para ambos; outra é ter que avaliar um povoamento florestal que ainda não atingiu seu estado de maturação ou idade de corte. Nesse caso, há vários custos e receitas que ocorrerão no futuro os quais deverão ser considerados na análise (SILVA et al., 2005).

\section{RESULTADOS E DISCUSSÃO}

Para cada um dos métodos avaliados, foi calculado o valor de venda sem a terra (apenas a floresta) e com a terra (floresta mais propriedade).

\subsection{Valor de mercado do povoamento florestal}

Para o cálculo do valor de mercado da propriedade rural, foram considerados o valor da terra nua e a produtividade da floresta no momento da comercialização do imóvel rural, com e sem inclusão da terra. Os resultados obtidos são apresentados na Tabela 3.

Tabela 3 - Valor de mercado e idade da floresta.

Table 3 - Market value and forest age.

\begin{tabular}{cccc}
\hline $\begin{array}{c}\text { Idade da } \\
\text { floresta } \\
\text { (meses) }\end{array}$ & $\begin{array}{c}\text { Produção } \\
\left(\mathrm{m}^{3} / \text { ha) }\right.\end{array}$ & $\begin{array}{c}\text { Valor de Mercado } \\
\text { Apenas a floresta } \\
\text { (R\$/ha) }\end{array}$ & $\begin{array}{c}\text { Valor de Mercado } \\
\text { A terra e a floresta } \\
\text { (R\$/ha) }\end{array}$ \\
\hline 0 & - & 0,00 & $2.843,25$ \\
12 & 44,3 & 627,00 & $3.470,20$ \\
24 & 81,8 & $1.275,40$ & $4.118,60$ \\
36 & 145 & $2.424,30$ & $5.267,60$ \\
48 & 239,4 & $4.173,30$ & $7.016,60$ \\
60 & 351,1 & $6.374,20$ & $9.217,40$ \\
72 & 436,9 & $8.677,50$ & $11.520,80$ \\
84 & 467,2 & $10.808,60$ & $13.651,80$ \\
\hline
\end{tabular}

Cerne, Lavras, v. 17, n. 2, p. 209-213, abr./jun. 2011 
Pode-se observar que quanto mais avançada a idade da floresta, maior o valor de mercado do imóvel a ser comercializado.

\subsection{Valor de custo do povoamento florestal}

Para o cálculo deste método, são computados todos os custos já ocorridos na implantação e manutenção da floresta até o momento da venda, ou seja, é o valor que um comprador gastaria para implantar a floresta até a idade em questão. Vale ressaltar que os custos de anos anteriores são capitalizados para o ano em que se deseja comercializar a floresta. A partir dos dados obtidos e do cenário proposto, os resultados obtidos como valor de comercialização da propriedade rural podem ser observados na Tabela 4.

Tabela 4 - Valor de custo e idade da floresta.

Table 4 - Cost value and forest age.

\begin{tabular}{ccc}
\hline $\begin{array}{c}\text { Idade da floresta } \\
\text { (em meses) }\end{array}$ & $\begin{array}{c}\text { Valor de Custo } \\
\text { Apenas a floresta } \\
\text { (R\$/ha) }\end{array}$ & $\begin{array}{c}\text { Valor de Custo } \\
\text { A terra e a floresta } \\
\text { (R\$/ha) }\end{array}$ \\
\hline 0 & $1.811,00$ & $4.654,30$ \\
12 & $2.554,40$ & $5.397,70$ \\
24 & $3.372,20$ & $6.215,40$ \\
36 & $4.271,70$ & $7.115,00$ \\
48 & $5.261,20$ & $8.104,50$ \\
60 & $6.349,70$ & $9.192,90$ \\
72 & $7.547,00$ & $10.390,20$ \\
84 & $8.864,00$ & $11.707,30$ \\
\hline
\end{tabular}

\subsection{Valor produtivo do povoamento florestal}

Diferentemente do valor de custo, este método contempla os custos e receitas futuras, ou seja, não considera o que já foi investido. É feita uma descapitalização das receitas futuras para o ano em que se deseja negociar o imóvel rural. Os resultados obtidos são apresentados na Tabela 5.

\subsection{Comparação entre os métodos de avaliação}

Uma vez feita a análise de cada método proposto separadamente, é interessante compará-los para que seja feita uma análise mais criteriosa entre eles. As Figuras 1 e 2 demonstram a relação existente entre os métodos de avaliação estudados, com e sem a inclusão das terras.
Tabela 5 - Valor Produtivo e a idade da floresta.

Table 5 - Productive value and forest age.

\begin{tabular}{ccc}
\hline $\begin{array}{l}\text { Idade da } \\
\begin{array}{c}\text { floresta } \\
\text { (em meses) }\end{array}\end{array}$ & $\begin{array}{c}\text { Valor Produtivo } \\
\text { aos } 7 \text { anos sem terra } \\
(\mathrm{R} \$ / \mathrm{ha})\end{array}$ & $\begin{array}{c}\text { Valor Produtivo } \\
\text { aos } 7 \text { anos com terra } \\
(\mathrm{R} \$ / \mathrm{ha})\end{array}$ \\
\hline 0 & $2.808,90$ & $5.652,10$ \\
12 & $3.652,10$ & $6.495,30$ \\
24 & $4.579,60$ & $7.422,90$ \\
36 & $5.599,90$ & $8.443,10$ \\
48 & $6.722,20$ & $9.565,50$ \\
60 & $7.956,80$ & $10.800,00$ \\
72 & $9.314,80$ & $12.158,00$ \\
84 & $10.808,60$ & $13.651,80$ \\
\hline
\end{tabular}

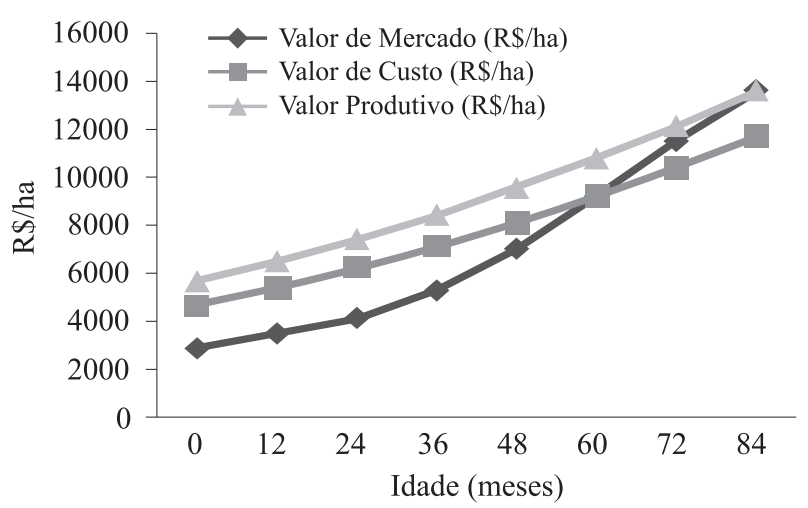

Figura 1 - Comparação entre os métodos de avaliação, utilizando a floresta com a inclusão da terra.

Figure 1 - Comparison among assessment methods, using forest with inclusion of land.

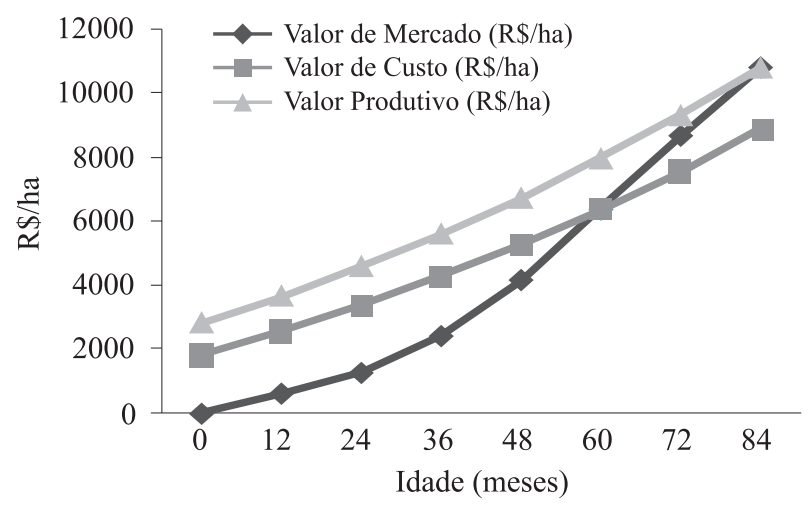

Figura 2 - Comparação entre os métodos de avaliação, utilizando a floresta sem a inclusão da terra.

Figure 2 - Comparison among assessment methods, using forest without inclusion of land. 
Pela análise dos gráficos, fica claro que existe uma diferença significativa entre os métodos de avaliação utilizados e algumas características destes são muito importantes. O valor de mercado é um método interessante de ser utilizado em idades mais avançadas da floresta, uma vez que esta já possui madeira de maior valor comercial e, por conseqüência, a valorização do imóvel também é maior.

Outro aspecto importante é que, no final do ciclo, os métodos valor de mercado e valor produtivo possuem mesmo valor no final do horizonte de 7 anos. O valor de custo mostrou-se inferior ao valor produtivo em todas as idades da floresta, o que indica que o valor potencial da floresta é muito maior que o valor já investido.

Em valores absolutos, no início da implantação do projeto, o valor do imóvel foi de $\mathrm{R} \$ 0,00 /$ ha valor de mercado; R\$1.811,00/ha valor de custo; $\mathrm{R} \$ 2.808,9 /$ ha valor produtivo. Esses valores não consideram a venda da terra, apenas a floresta. Já no final do ciclo, aos 7 anos, foi observado um outro cenário, em que o valor da terra foi de $\mathrm{R} \$ 13.651,8 /$ ha pelos métodos de valor de mercado e valor produtivo e foi de $\mathrm{R} \$ 11.707,30 /$ ha pelo método valor de custo.

Assim, a diferença entre o Valor Produtivo e o Valor de Custo é exatamente o lucro proporcionado pelo projeto. Caso o preço ou a produção caia, diminuindo a margem de lucro, esses métodos se aproximam.

\section{CONCLUSÕES}

Os métodos avaliados apresentaram grandes diferenças entre si, principalmente no valor de mercado, que teve um comportamento bem diferente dos outros dois métodos, uma vez que, com o crescimento da floresta e valorização da madeira, o valor do imóvel teve um acréscimo significativo.

Os métodos Valor de Mercado e Valor Produtivo tiveram um mesmo comportamento com o desenvolvimento da floresta, uma tendência linear crescente. Em termos absolutos, o valor de custo foi sempre menor que o valor produtivo.

O método mais utilizado é o Valor de Mercado, contudo recomenda-se utilizar mais de um método, pois deste modo a análise fica mais consistente, permitindo um maior poder de negociação.

\section{REFERÊNCIAS}

AGRIANUAL. Anuário da agricultura brasileira. São Paulo: Instituto FNP, 2007.

ASSOCIAÇÃO BRASILEIRA DE NORMAS TÉCNICAS. NBR 14653-3: avaliação de bens, parte 3: imóveis rurais. Rio de Janeiro, 2004.

DESLANDES, C. A. Avaliação de imóveis rurais. Viçosa, MG: Aprenda Fácil, 2002.

FIKER, J. Avaliação de imóveis urbanos. 5. ed. São Paulo: PINI, 1997.

OLIVEIRA, M. L. R. de. Mensuração e modelagem do crescimento e da produção de povoamentos não-desbastados de clones de eucalipto. 2007. 115 p. Tese (Doutorado em Ciência Florestal) - Universidade Federal de Viçosa, Viçosa, 2007.

SILVA, M. L.; JACOVINE, L. A. G.; VALVERDE, S. R. Economia florestal. 2. ed. Viçosa, MG: UFV, 2005. 